Bond University

Research Repository

\title{
Nutrition screening in geriatric rehabilitation: Criterion (concurrent and predictive) validity of the Malnutrition Screening Tool and the Mini Nutritional Assessment-Short Form
}

Marshall, Skye; Young, Adrienne; Bauer, Judith; Isenring, Elizabeth

Published in:

Journal of the Academy of Nutrition and Dietetics

DOI:

10.1016/j.jand.2015.06.012

Licence:

CC BY-NC-ND

Link to output in Bond University research repository.

Recommended citation(APA):

Marshall, S., Young, A., Bauer, J., \& Isenring, E. (2016). Nutrition screening in geriatric rehabilitation: Criterion (concurrent and predictive) validity of the Malnutrition Screening Tool and the Mini Nutritional Assessment-Short Form. Journal of the Academy of Nutrition and Dietetics, 116(5), 795-801.

https://doi.org/10.1016/j.jand.2015.06.012

\section{General rights}

Copyright and moral rights for the publications made accessible in the public portal are retained by the authors and/or other copyright owners and it is a condition of accessing publications that users recognise and abide by the legal requirements associated with these rights.

For more information, or if you believe that this document breaches copyright, please contact the Bond University research repository coordinator 
1 Nutrition screening in geriatric rehabilitation: Criterion (concurrent and predictive) validity

\section{(MNA-SF)}

Ms Skye Marshall ${ }^{\mathrm{a}, \mathrm{b}}$, Dr. Adrienne Young ${ }^{\mathrm{c}}$, A/Prof. Judith Bauer ${ }^{\mathrm{d}}$, Prof. Elizabeth Isenring ${ }^{\mathrm{e}}$

${ }^{\text {a }}$ BNutr\&Diet(Hons), Accredited Practising Dietitian, PhD Candidate, Faculty of Health Sciences and Medicine, Bond University

${ }^{\mathrm{b}}$ Corresponding author. Bond Institute of Health and Sport, Robina, Queensland, 4226, Australia.

Telephone: +61 75595 5530, Fax: +61 75595 3524, skye.marshall@ student.bond.edu.au c BHlthSci (Nutr\&Diet)(Hons), Accredited Practising Dietitian, PhD. Royal Brisbane and Women's Hospital, Herston, Queensland. Level 2 Dr James Mayne Building, Herston Queensland, 4034, telephone (07) 3646 8268, Adrienne_Young@ health.qld.gov.au

${ }^{\mathrm{d}}$ Accredited Practising Dietitian, Associate Professor Nutrition and Dietetics, School of Human Movement and Nutrition Sciences, Building 26, the University of Queensland, Brisbane, Queensland, 4072, Australia. Phone: 61+ 07336 56982, Fax: 61+ 073365 6877, j.bauer1@uq.edu.au

${ }^{\mathrm{e}}$ Accredited Practising Dietitian, Professor Nutrition and Dietetics, Faculty of Health Sciences and Medicine, Bond University. Bond Institute of Health and Sport, Robina, Queensland, 4226, Australia. Telephone: +61 75595 5530, Fax: +61 75595 3524, lisenrin@ bond.edu.au

\section{Keywords: nutrition screening, malnutrition, rehabilitation, rural, aged}




\section{Abstract}

Background: Nutrition screening is required for early identification and treatment of patients at risk of malnutrition so that clinical outcomes may be improved and health care costs reduced. Objectives: To determine the criterion (concurrent and predictive) validity of the Malnutrition Screening Tool (MST) and Mini Nutritional Assessment-Short Form (MNA-SF) in older adults admitted to inpatient rehabilitation facilities. Design: Observational, prospective cohort. Participants/setting: $\mathrm{n}=57$ older adults $\geq 65$ years, median age $79.1 \mathrm{y}( \pm 7.3 \mathrm{y})$ from two rural rehabilitation units in New South Wales, Australia. Main outcome measurements: MST, MNASF, ICD-10-AM classification of malnutrition, rehospitalization, length of stay, admission to a residential aged care facility and discharge location. Statistical analysis performed: Measures of diagnostic accuracy with $95 \%$ confidence intervals generated from a contingency table, MannWhitney U test and chi-squared test. Results: When compared to the ICD-10-AM criteria, the MST showed stronger diagnostic accuracy (sensitivity $80.8 \%$, specificity $67.7 \%$ ) than the MNA-SF (sensitivity $100 \%$, specificity $22.6 \%$ ). Neither the MST nor the MNA-SF were able to predict rehospitalization, institutionalization or discharge location. Conclusion: The MST showed good concurrent validity and can be considered an appropriate nutrition screening tool in geriatric rehabilitation. The MNA-SF may overestimate the risk of malnutrition in this population. The predictive validity could not be established for either screening tool. 


\section{Nutrition screening in geriatric rehabilitation: Criterion (concurrent and predictive) validity} of the Malnutrition Screening Tool (MST) and the Mini Nutritional Assessment-Short Form (MNA-SF)

\section{Introduction}

Nutrition screening is required for early identification and treatment of patients at risk of proteinenergy malnutrition (termed "malnutrition" throughout) and should occur routinely in all health care settings ${ }^{1}$. Nutrition screening tools are used to identify risk of malnutrition ${ }^{2}$. They should be quick and simple to implement and able to be used by any trained person or the patient themselves. Once risk is identified, a diagnosis of malnutrition should be made by a qualified health professional, such as a Registered Dietitian Nutritionist, following a more comprehensive assessment of nutrition status $^{3}$. It is critical that nutrition screening tools are validated for the population to which they are applied so that patient outcomes may be improved and resources are used efficaciously ${ }^{3}$.

Rehabilitation facilities are sub-acute health care facilities where patients are admitted when they require medical and multi-disciplinary treatment with the purpose of increasing independence ${ }^{1}$. Rehabilitation patients typically have a chronic illness, such as chronic obstructive pulmonary disease or Parkinson's disease, or are recovering from an acute illness, such as a stroke or hipfracture. Due to the nature of rehabilitation facilities, the majority of patients are older adults. Malnutrition in older adults admitted to rehabilitation is associated with adverse clinical outcomes and mortality during admission ${ }^{4}$; and poorer quality of life and increased levels of physical dysfunction, hospitalization, institutionalization and mortality once discharged to the community ${ }^{5,6}$. Older adults are often transferred to rehabilitation from acute care facilities where they may have developed malnutrition as a result of their illness or imposed treatments. Therefore early and accurate identification of nutrition risk when admitted to rehabilitation facilities is important for attaining a successful rehabilitation outcome and decreasing the economic burden of malnutrition in the older adult community. 
65 Skipper et al. ${ }^{7}$ have recently reviewed the nutrition screening tools that have been developed for 66 identifying risk of malnutrition in a variety of settings, including the Malnutrition Screening Tool 67 (MST) ${ }^{8}$. The review concluded that the MST was the only nutrition screening tool of the 11 identified which was supported by studies espousing its validity and reliability. The MST has been

widely adopted by health care facilities due to low cost of implementation and low participation burden ${ }^{8}$. Since its development in acute care patients, the MST has also been shown to be valid in oncology outpatients and more recently in residential aged care facilities (RACF) ${ }^{8-10}$. In the rehabilitation setting, there are only two screening tools which have been evaluated for validity. These include the Mini Nutrition Assessment-Short Form (MNA-SF) ${ }^{11}$ and the Rapid Screen ${ }^{12}$. The MNA-SF showed substantial agreement with the full MNA (kappa 0.626, 95\% CI 0.507-0.744) ${ }^{13}$ and the Rapid Screen reported moderate sensitivity (78.6\%) and excellent specificity (97.3\%) ${ }^{12}$ compared with a standardized nutrition assessment in geriatric rehabilitation. However, the MNASF has not been evaluated for its sensitivity or specificity nor has it been evaluated using a benchmark unrelated to the MNA. The MST has not been evaluated in geriatric rehabilitation despite being frequently used by practitioners. Therefore, the aim of this study was to determine the criterion (concurrent and predictive) validity of the MST and MNA-SF in older adults admitted to inpatient rehabilitation facilities. 


\section{Materials and methods}

Study sample

Participants were older adults admitted to one of two public rehabilitation units in the same local health district in rural New South Wales, Australia ${ }^{14}$. Study centers were chosen by convenience sampling based on location, and participants consecutively sampled. Participants were Englishspeaking inpatients $\geq 65$ years admitted to the participating rehabilitation units, community-dwelling residents prior to admission, if they were admitted with the expectation they would return to the community, and had an informal caregiver. This study was conducted as part of the MARRC (Malnutrition in the Australian Rural Rehabilitation Community) Study (Trial version 2.0, 9 May 2013) which has been registered at the Australian New Zealand Clinical Trials Registry (ACTRN12613000518763) and has received ethical and governance approval (North Coast NSW Human Research Ethics Committee: LNR 063, G108; School of Human Movement Studies Ethics Committee: HMS13/0731). Written informed consent was obtained from all participants and/or their guardians.

\section{$\underline{\text { Data collection }}$}

Data used in this observational, prospective cohort study were collected from August 2013 to February 2014. Participant characteristics and nutrition screening and assessment tools were all collected or completed on behalf of the participant by the primary researcher during an interview at the bedside (median of two days following admission) and were further supported by information from medical records, rehabilitation staff or the patient's informal caregiver.

\section{Nutrition screening}

The MST consists of two questions relating to recent unintentional weight loss and eating poorly, and was scored according to the Queensland Government's resource "Malnutrition. Is your patient at risk?" ${ }^{15}$. A score of 2 or higher indicates the patient should be referred to a dietitian to attend nutrition assessment and intervention as appropriate ${ }^{8}$. Therefore, for the assessment of criterion 
validity, a score of 0-1 was used to indicate "well-nourished" and $\geq 2$ was used to indicate "risk of malnutrition". The MST was not completed as a separate tool for each participant, but rather a range of data were obtained during a full nutrition assessment including the two MST questions, which were later used to complete the MST, a method reported by previous researchers ${ }^{16}$. Weight loss was considered in the six months leading up to the assessment.

The MNA-SF was completed as a separate tool. The MNA-SF consists of six questions and is scored $0-14$ where a score of $0-7$ indicates 'malnourished', $8-11$ indicates 'at risk of malnutrition' and $12-14$ indicates normal nutrition status ${ }^{17}$. For this study, an MNA-SF score of $12-14$ was considered 'well-nourished' and $0-11$ 'risk of malnutrition'.

\section{Nutrition assessment}

There is no gold standard for diagnosing malnutrition. The International Statistical Classification of Diseases and Health Related Problems $10^{\text {th }}$ revision Australian Modification (sixth edition, ICD10-AM) criteria are the recognized standard diagnostic criteria for the identification, documentation and coding of protein-energy malnutrition and are used to provide case-mix funding reimbursements (table 1). For this reason, the ICD-10-AM classification for malnutrition is an appropriate benchmark to establish the concurrent validity of a nutrition screening tool, and has been used as the standard against which nutrition screening and assessment tools have been validated $^{18,19}$. The ICD-10-AM classification involves an evaluation of body mass index (BMI) $\left(<18.5 \mathrm{~kg} / \mathrm{m}^{2}\right)$ to detect chronic malnutrition, or weight loss with suboptimal dietary intake resulting in fat and/or muscle wasting to detect acute malnutrition. Failure to identify patients at risk of malnutrition in the health care setting can negatively impact funding ${ }^{20}$; therefore, the nutrition screening and assessment method used must be in agreement with the ICD-10-AM criteria to ensure resources are available for treatment. During nutrition assessment, the components of BMI, weight loss in the six months prior to assessment, a physical evaluation of fat stores and muscle status, and a brief dietary assessment were recorded and used to inform the ICD-10-AM classification of 
malnutrition for each participant. Any participant meeting the ICD-10-AM criteria of mild, moderate or severe malnutrition (as per table 1) was considered to have the condition 'malnutrition', and if they did not meet any ICD-10-AM criterion they were considered 'wellnourished'.

Weight (kg) was measured to the first decimal point by Tanita InnerScan Body Composition Monitor scales model: BC-541 (2005, Tanita Corporation, Tokyo, Japan) by the researcher. If a participant was non-weight bearing or unable to stand unassisted then the rehabilitation wards scales were used (chair or roll-on scales). All three scales were within $0.1 \mathrm{~kg}$ calibration. Weights recorded for amputees were adjusted ${ }^{21}$. Due to the expected high number of bed- or chair- bound participants admitted to rehabilitation, height was calculated by knee height. A sliding knee height caliper was used to measure the knee height, which was then entered into a population specific formula to estimate the true height ${ }^{21}$. BMI $\left(\mathrm{kg} / \mathrm{m}^{2}\right)$ was calculated using measured weight and estimated height. For describing this sample of older adults, a normal BMI was considered $22-$ $27 \mathrm{~kg} / \mathrm{m}^{2},<22 \mathrm{~kg} / \mathrm{m}^{2}$ was considered underweight and $>27 \mathrm{~kg} / \mathrm{m}^{2}$ overweight $/$ obese ${ }^{22,23}$.

\section{Health and aged care service use}

Increased health and aged care service use have been associated with malnutrition in the geriatric rehabilitation setting and reflects patient wellbeing and health and aged care costs ${ }^{5}$. Therefore, discharge location (home/other), rehospitalization (total length of stay of subsequent rehabilitation and acute care admissions) and institutionalization (admission to RACF; yes/no) were chosen to evaluate predictive validity. Discharge location was measured at the time of discharge.

Rehospitalization and admission to an RACF were measured three months post-discharge to the community. Data were obtained from the health service's electronic admissions database and confirmed by telephone or in-home interviews.

\section{Statistical approach}


All statistical analysis was completed using SPSS Version 22.0 2013 (IBM SPSS Statistics for

Windows. Armonk, NY: IBM Corp.). Significance was considered at the $P<0.05$ level. Descriptive statistics (mean \pm standard deviation, median and interquartile range) were used to characterize the sample population. Chi-squared and independent sample t-tests (or Mann-Whitney if nonparametric) were used to assess for a significant difference in descriptors of the sample population by rehabilitation center.

Criterion validity represents how well a particular variable predicts an outcome compared to other variables, and encompasses concurrent and predictive validity ${ }^{24}$. Concurrent validity is determined by comparing the score of a new measurement to the score of a well-established measurement for the same construct, in this case comparing the MST and MNA-SF nutrition risk categories with a malnutrition diagnosis as per ICD-10-AM classification of malnutrition. Predictive validity is established when the score of a particular measurement makes an accurate prediction about the construct they represent, in this case we determine if the MST and MNA-SF "risk of malnutrition" categories are able to detect the difference in rates of rehospitalization, institutionalization and discharge location, all of which are health-related outcomes which are associated with malnutrition.

To determine the concurrent validity of the MST and MNA-SF in this sample, measures of diagnostic accuracy were determined. The sensitivity (malnourished/risk of malnutrition correctly identified as such), specificity (well-nourished correctly identified as such), positive predictive value (PPV, correctly identified as malnourished/risk of malnutrition within the malnourished sample), negative predictive value (NPV, correctly identified as well-nourished within wellnourished sample), a weighted kappa statistic and diagnostic odds ratio (DOR) with the 95\% confidence intervals $(\mathrm{CI})$ were determined using contingency tables against the ICD-10-AM classification of malnutrition. Sensitivity was considered of higher importance than specificity and a-priori values of $80 \%$ or more for sensitivity and $60 \%$ or more for specificity were considered to indicate a good nutrition screening tool ${ }^{8}$. The DOR is a global measure of diagnostic accuracy, 
182 where a score of one indicates the test is equally likely to predict a positive outcome whatever the 183 true condition and the higher the ratio the better the test performance ${ }^{25}$.

184 To evaluate the predictive validity of the MST and MNA-SF, the categories of 'well-nourished' and 185 'risk of malnutrition' were tested for significance with the longitudinal outcomes of 186 rehospitalization length of stay, discharge location and admission to an RACF using the Mann187 Whitney U test and chi-squared test. 


\section{Results}

189

190

191

192

Study participants

Over the study recruitment period, 57 consecutive rehabilitation inpatients consented to participate in the study (response rate of $98 \%)$. The mean age was $79.1 \mathrm{y}( \pm 7.3 \mathrm{y})$; however there was a significant difference in age between sites (77.5y versus $81.4 \mathrm{y})$. Fifty-four percent of participants were at risk of malnutrition according to the MST, $88 \%$ according to the MNA-SF and $46 \%$ were malnourished according to the ICD-10-AM criteria. Site B had a significantly higher proportion of participants considered "at risk of malnutrition" than site A according to the MST. Ad hoc analysis reveals this is due to a higher proportion of participants at site B with decreased dietary intake as well as losing a larger amount of weight. Participant characteristics are shown in table 2.

\section{Concurrent and predictive validity of the Malnutrition Screening Tool and Mini Nutritional}

\section{Assessment - Short Form}

In evaluating its concurrent validity, the MST exceeded a-priori values for sensitivity and specificity and had strong PPV (67.7, 95\%CI: 48.6-83.3) and NPV (80.8, 95\%CI: 60.6-93.4) (table

3). The MNA-SF showed perfect sensitivity and NPV but only $22.6 \%$ (95\%CI: 11.4-39.8) specificity and 52\% (95\%CI: 37.4-66.3) PPV. The DOR of the MST and MNA-SF were similar, showing the screening tools have some diagnostic value; however the wide $95 \%$ confidence interval of the MNA-SF DOR shows this variable may be underpowered and is unreliable. The kappa statistic for the MST showed 'moderate agreement' with the ICD-10-AM classification of malnutrition, whereas the kappa statistic for the MNA-SF was considered 'fair agreement'. In regards to predictive validity, neither tool was able to detect a significant difference in rehospitalization length of stay, admission to an RACF or discharge location in this sample. Prevalence of these outcomes will be reported elsewhere (Marshall et al., 2015, unpublished data). 


\section{Discussion}

212 This is the first study to evaluate the criterion validity of the MST in the rehabilitation setting, and 213 to evaluate the concurrent validity of the MNA-SF in the rehabilitation setting using a benchmark unrelated to the MNA ${ }^{1}$. The MST showed strong concurrent validity when compared to the ICD10-AM classification of malnutrition in this sample of older adults admitted to rehabilitation. However, the MNA-SF may overestimate risk of malnutrition when compared to ICD-10-AM criteria. Neither tool was able to predict health and aged care use.

The MST performed stronger in this geriatric rehabilitation sample than reported in an acute hipfracture population (kappa 0.363 , sensitivity $60 \%$ and specificity $76 \%$ ), which also used the ICD10-AM classification as a benchmark ${ }^{19}$. This difference in sensitivity and specificity between the two similar populations may be due to how the MST was scored, where the hip-fracture study only scored points for decreased oral intake due to decreased appetite, as opposed to decreased oral intake for any reason, as used in this study. These results suggest that the current method of scoring the MST in older adults may be superior. In the study by Isenring et al. ${ }^{10}$ which scored the MST to include decreased oral intake for any reason, the MST also showed strong concurrent validity when compared to the Subjective Global Assessment (kappa 0.806, sensitivity 89\% and specificity 94\%) and MNA (kappa 0.501, sensitivity 94\% and specificity $81 \%$ ) in an RACF setting. There has only been one study evaluating the predictive validity of the MST, where it was found to predict length of stay in 408 adult acute hospital patients ${ }^{8}$.

The low specificity of the MNA-SF was unexpected, as this tool performed better in the acute hipfracture population, though it still tended to over-estimate risk of malnutrition when using $<12$ as 233 showed 'substantial agreement' (kappa 0.626) in a previous study evaluating the validity of the 234 MNA-SF in the rehabilitation setting; however, the study did not report sensitivity and specificity 235 and the full MNA was used as the benchmark ${ }^{13}$. A poor performance of the MNA-SF against other 
nutrition assessments may be due to the focus of the MNA/MNA-SF being on early identification of malnutrition risk, whereas assessments such as SGA and ICD-10-AM focus on diagnosing existing malnutrition ${ }^{26}$. Therefore an over-classification of well-nourished patients as at risk of malnutrition may be appropriate for some well-resourced settings, where prevention of malnutrition is the focus as opposed to treatment ${ }^{26-28}$. Despite the MNA-SF's poor specificity, 'fair' kappa statistic and not being able to predict patient outcomes in this study, nutritional risk determined by the MNA-SF has previously found to be associated with increased risk of institutionalization and decreased physical function and quality of life in geriatric rehabilitation ${ }^{29}$. Furthermore, the original authors suggested lowering the cut-off value of the MNA-SF if an improvement in specificity is required ${ }^{11}$.

The inability of the MST and MNA-SF to detect a difference in health and aged care service use may be due to a relatively small sample size. However, as the current sample size had enough power to detect the difference in these outcomes following a diagnosis of malnutrition using the ICD-10-AM criteria (Marshall et al., 2015, unpublished data), it may have clinical implications that the MST and MNA-SF did not display predictive validity. These results emphasize the importance of following nutrition screening with a full nutrition assessment in order for resources to be used appropriately and to ensure adequate funding of health care facilities.

\section{Limitations}

There is risk of bias with the same researcher conducting the screening and assessment; however, independent review of assessments by experienced practitioners were conducted to limit bias. As both the MST and MNA-SF were completed by a trained dietitian (Accredited Practising Dietitian) during a full nutrition assessment, the accuracy of tool completion by a person without a nutrition background, such as nursing staff, may not be as high. The next step in evaluating the validity of the MST and MNA-SF should be a larger study with tools completed by trained non-dietetic staff during admission and/or by patient self-completion. Further research comparing the Rapid Screen with the MST and MNA-SF would also be of interest. A limitation of using the ICD-10-AM 
261 classification of malnutrition as the standard in this population is the BMI cut-off of $<18.5 \mathrm{~kg} / \mathrm{m}^{2}$, 262 which is likely to be too low for an older population, where a BMI of $\leq 22 \mathrm{~kg} / \mathrm{m}^{2}$ is generally 263 considered underweight ${ }^{22,23}$. This may increase the rate of type II errors, where a chronically 264 malnourished participant was considered well-nourished, and may have caused a decrease in the 265 sensitivity of the nutrition screening tools when compared to the ICD-10-AM classifications. 


\section{Conclusions}

268 The MST is appropriate for use as a nutrition screening tool in geriatric rehabilitation; however, the 269 MNA-SF may overestimate the risk of malnutrition. Neither the MST nor the MNA-SF displayed 270 predictive validity in this sample of older adults admitted to rural rehabilitation units. Nutrition

271 screening should be followed by a full nutrition assessment to identify patients in need of nutrition 272 intervention so that resources may be used efficaciously and patient outcomes improved. 


\section{References}

1. Watterson C, Fraser A, Banks M, et al. Evidence based practice guidelines for the nutritional management of malnutrition in patients across the continuum of care. Nutr Diet. 2009;66(Suppl 3):S1 - S34.

2. Field L, Hand R. Differentiating Malnutrition Screening and Assessment: A Nutrition Care Process Perspective. J Acad Nutr Diet. 2015;115(5):824-828.

3. Lacey K, Prichett E. Nutrition Care Process and Model: ADA adopts road map to quality care and outcomes management. J Am Diet Assoc. 2003;103(8):1061-1072.

4. Donini LM, De Bernardini L, De Felice MR, Savina C, Coletti C, Cannella C. Effect of nutritional status on clinical outcome in a population of geriatric rehabilitation patients. Aging Clin Exp Res. 2004;16(2):132-138.

5. Marshall S, Bauer J, Isenring E. The consequences of malnutrition following discharge from rehabilitation to the community: a systematic review of current evidence in older adults. J Hum Nutr Diet. 2013;27:133-141.

6. Marshall S, Young A, Bauer J, Isenring E. Malnourished older adults admitted to rehabilitation in rural New South Wales remain malnourished throughout rehabilitation and once discharged back to the community: a prospective cohort study J Aging Res Clin Practice. 2015;In Press.

7. Skipper A, Ferguson M, Thompson K, Castellanos VH, Porcari J. Nutrition screening tools. J Parenter Enteral Nutr. 2012;36(3):292-298.

8. Ferguson M, Capra S, Bauer J, Banks M. Development of a valid and reliable malnutrition screening tool for adult acute hospital patients. Nutr. 1999;15(6):458464. 
9. Ferguson M, Bauer J, Gallagher B, Capra S, Christie D, Mason B. Validation of a malnutrition screening tool for patients receiving radiotherapy. Australas Radiol. 1999;43(3):325-327.

10. Isenring EA, Banks M, Ferguson M, Bauer JD. Beyond malnutrition screening: Appropriate methods to guide nutrition care for aged care residents. $J$ Acad Nutr Diet. 2012;112(3):376-381.

11. Rubenstein LZ, Harker JO, Salvà A, Guigoz Y, Vellas B. Screening for undernutrition in geriatric practice developing the Short-Form Mini-Nutritional Assessment (MNASF). Series. A: J Gerontol. 2001;56(6):M366-M372.

12. Visvanathan R, Penhall R, Chapman I. Nutritional screening of older people in a subacute care facility in Australia and its relation to discharge outcomes. Age Ageing. 2004;33(3):260-265.

13. Kaiser MJ, Bauer JM, Uter W, et al. Prospective validation of the modified Mini Nutritional Assessment Short-Forms in the community, nursing home, and rehabilitation setting. J Am Geriatr Soc. 2011;59(11):2124-2128.

14. Rural, regional and remote health: a guide to remoteness classifications. AIHW cat. no. PHE 53. Published 2004. Canberra: AIHW.

15. Ferguson M, Capra S, Bauer J, Banks M. Malnutrition. Is your patient at risk? Nutrition Support Resources: NEMO Nutrition Support Group, Queensland Governement, Queensland Health; 1999.

16. Isenring EA, Bauer JD, Banks M, Gaskill D. The Malnutrition Screening Tool is a useful tool for identifying malnutrition risk in residential aged care. J Hum Nutr Diet. 2009;22(6):545-550.

17. Vellas B, Villars H, Abellan G, et al. Overview of the MNA-Its history and challenges. J Nutr Health Aging. 2006;10(6):456-465. 
18. Bell J, Bauer J, Capra S, Pulle R. Concurrent and predictive evaluation of malnutrition diagnostic measures in hip fracture inpatients: a diagnostic accuracy study. Eur J Clin Nutr. 2014;68(3):358-362.

19. Bell JJ, Bauer JD, Capra S, Pulle RC. Quick and Easy Is Not without Cost: Implications of Poorly Performing Nutrition Screening Tools in Hip Fracture. J Am Geriatr Soc. 2014;62(2):237-243.

20. Agarwal E, Ferguson M, Banks M, Bauer J, Capra S, Isenring E. Malnutrition coding shortfalls in Australian and New Zealand hospitals. Nutr Diet. 2014;DOI:10.1111/1747-0080.12116.

21. Nutrition screening as easy as MNA: A guide to completing the Mini Nutritional Assessment (MNA). Swizterland: Nestle Nutrition Institute.

22. Nutrient Reference Values for Australia and New Zealand Including Recommended Dietary Intakes. Canberra: National Health and Medical Resarch Council; 2005.

23. Perissinotto E, Pisent C, Sergi G, Grigoletto F, Enzi G. Anthropometric measurements in the elderly: age and gender differences. Br J Nutr. 2002;87(2):177-186.

24. Laerd Statistics, Lund Research. Criterion validity (concurrent and predictive validity). http://dissertation.laerd.com/criterion-validity-concurrent-and-predictivevalidity.php. Published 2012. Accessed November 8, 2014.

25. Šimundić A-M. Measures of diagnostic accuracy: basic definitions. Med Biol Sci. 2008;22(4):61-65.

26. Young AM, Kidston S, Banks MD, Mudge AM, Isenring EA. Malnutrition screening tools: comparison against two validated nutrition assessment methods in older medical inpatients. Nutr. 2013;29(1):101-106. 
27. Persson MD, Brismar KE, Katzarski KS, Nordenström J, Cederholm TE. Nutritional status using Mini Nutritional Assessment and Subjective Global Assessment predict mortality in geriatric patients. J Am Geriatr Soc. 2002;50(12):1996-2002.

28. Martins CPAL, Correia JR, do Amaral TF. Undernutrition risk screening and length of stay of hospitalized elderly. J Nutr Elder. 2006;25(2):5-21.

29. Neumann SA, Miller MD, Daniels L, Crotty M. Nutritional status and clinical outcomes of older patients in rehabilitation. J Hum Nutr Diet. 2005;18(2):129-136.

30. Australian coding standards for I.C.D.-10-AM. Sydney: National Centre for Classification in Health; 2008.

31. Landis JR, Koch GG. The measurement of observer agreement for categorical data. Biometrics. 1977;33:159-174.

32. Pagano M, Gauvreau K, Pagano M. Principles of biostatistics. Vol 2: Duxbury Pacific Grove, CA; 2000.

33. Deeks JJ, Higgins JP. Statistical algorithms in Review Manager 5. Statistical Methods Group of The Cochrane Collaboration. 2010:1-11.

34. Glas AS, Lijmer JG, Prins MH, Bonsel GJ, Bossuyt PM. The diagnostic odds ratio: a single indicator of test performance. J Clin Epidemiol. 2003;56(11):1129-1135. 


\section{Funding disclosure}

This study received no specific funding. SM is supported by an Australian Postgraduate Award throughout the duration of her PhD candidature.

\section{Conflict of interest disclosure}

The authors declare no conflicts of interest. SM was employed as a dietitian for New South Wales Health which occasionally involved a short-term contract to a rehabilitation ward. SM was not working at the rehabilitation wards at the time of data collection.

\section{Acknowledgements}

The authors gratefully acknowledge the assistance of E. Rathbone, Bond University, for contributing to the statistical approach and interpretation of data.

\section{Practice implications}

\section{What is the current knowledge on this topic?}

In the geriatric rehabilitation setting, the Malnutrition Screening Tool (MST) and the MNASF require further assessment of criterion (concurrent and predictive) validity.

How does this research add to knowledge on this topic?

This is the first study to evaluate the criterion validity of the MST in the rehabilitation setting, and to evaluate the concurrent validity of the MNA-SF in the rehabilitation setting using a benchmark unrelated to the MNA.

How might this knowledge impact current dietetics practice?

This study provides the first evidence in support of the MST in the geriatric rehabilitation setting. The MNA-SF overestimated risk of malnutrition in geriatric rehabilitation and may not be appropriate for use. 
Table 1: The International Statistical Classification of Diseases and Health Related Problems $10^{\text {th }}$ Revision Australian Modification (sixth edition, ICD-10-AM) classifications for proteinenergy malnutrition in adults ${ }^{30}$.

\begin{tabular}{|l|l|}
\hline Classification & Definition \\
\hline $\begin{array}{l}\text { E43: Unspecified severe } \\
\text { protein-energy } \\
\text { malnutrition }\end{array}$ & $\begin{array}{l}\text { In adults, } \mathrm{BMI}^{\mathrm{a}}<18.5 \mathrm{~kg}^{\mathrm{b}} / \mathrm{m}^{\mathrm{c} 2} \text { or unintentional loss of weight } \\
\text { loss of subcutaneous fat and/or severe muscle wasting }\end{array}$ \\
\hline $\begin{array}{l}\text { E44.0: Moderate } \\
\text { protein-energy } \\
\text { malnutrition }\end{array}$ & $\begin{array}{l}\text { In adults, BMI }<18.5 \mathrm{~kg} / \mathrm{m}^{2} \text { or unintentional loss of weight }(5- \\
9 \%) \text { with evidence of suboptimal intake resulting in moderate } \\
\text { loss of subcutaneous fat and } / \text { or moderate muscle wasting }\end{array}$ \\
\hline $\begin{array}{l}\text { E44.1: Mild protein- } \\
\text { energy malnutrition }\end{array}$ & $\begin{array}{l}\text { In adults, BMI }<18.5 \mathrm{~kg} / \mathrm{m}^{2} \text { or unintentional loss of weight }(5- \\
9 \%) \text { with evidence of suboptimal intake resulting in mild loss of } \\
\text { subcutaneous fat and } / \mathrm{or} \text { mild muscle wasting }\end{array}$ \\
\hline
\end{tabular}

a BMI, body mass index

${ }^{\mathrm{b}} \mathrm{kg}$, kilogram

${ }^{\mathrm{c}} \mathrm{m}$, meters 
Table 2: Characteristics of a cohort of 57 older adults admitted to rural rehabilitation facilities in New South Wales, Australia, overall and by facility

\begin{tabular}{|c|c|c|c|}
\hline Variable & Site A $(n=33)$ & Site B $(n=24)$ & $\begin{array}{c}\text { Total } \\
\text { participants } \\
(\mathbf{n}=\mathbf{5 7})\end{array}$ \\
\hline Age $\left(\right.$ years, mean $\left.\pm S^{a}{ }^{a}\right)$ & $77.5 \pm 7.5$ & $81.4 \pm 6.4^{*}$ & $79.1 \pm 7.3$ \\
\hline Female (\%) & 39.4 & 62.5 & 49.1 \\
\hline Weight $\left(\mathrm{kg}^{\mathrm{b}}\right.$, mean $\left.\pm \mathrm{SD}\right)$ & $70.5 \pm 18.9$ & $68.3 \pm 19.8$ & $69.6 \pm 19.1$ \\
\hline $\mathrm{BMI}^{\mathrm{c}}($ mean $\pm \mathrm{SD})$ & $25.4 \pm 6.4$ & $24.5 \pm 4.6$ & $25.0 \pm 5.7$ \\
\hline Underweight: $\mathrm{BMI}<22(\%)$ & 30.3 & 29.2 & 29.8 \\
\hline Overweight/obese: $\mathrm{BMI}>27(\%)$ & 30.3 & 29.2 & 29.8 \\
\hline $\begin{array}{l}\text { Admission source: } \\
\text { - } \quad \text { Acute health care facility }(\%) \\
\text { - } \quad \text { Community }(\%)\end{array}$ & $\begin{array}{l}81.8 \\
18.2\end{array}$ & $\begin{array}{l}91.7 \\
8.3\end{array}$ & $\begin{array}{l}86.0 \\
14.0\end{array}$ \\
\hline $\begin{array}{l}\text { Reason for admission: } \\
\text { - } \quad \text { Acute illness (\%) } \\
\text { - } \quad \text { Chronic illness }(\%)\end{array}$ & $\begin{array}{l}69.7 \\
30.3\end{array}$ & $\begin{array}{l}79.2 \\
20.8\end{array}$ & $\begin{array}{l}73.7 \\
26.3\end{array}$ \\
\hline $\begin{array}{l}\text { Cognitive impairment }{ }^{\mathrm{d}} \text { : } \\
\text { - } \operatorname{MMSE}^{\mathrm{e}}(\mathrm{n}=14)(\text { mean } \pm \mathrm{SD}) \\
-\quad 3 \mathrm{MS}^{\mathrm{f}} \text { Test }(\mathrm{n}=20)(\text { mean } \pm \text { SD })\end{array}$ & $\begin{array}{c}- \\
79.0 \pm 15.9\end{array}$ & $\begin{array}{c}23.1 \pm 3.4 \\
-\end{array}$ & - \\
\hline $\begin{array}{l}\text { Risk of malnutrition }(\%) \\
-\quad \text { MST }^{\mathrm{g}}(\text { score } \geq 2) \\
-\quad \text { MNA-SF }^{\mathrm{h}}(\text { score }<12)\end{array}$ & $\begin{array}{l}39.4 \\
84.5\end{array}$ & $\begin{array}{l}75.0^{*} \\
91.7\end{array}$ & $\begin{array}{l}54.4 \\
87.7\end{array}$ \\
\hline Malnourished $(\%)^{\mathrm{i}}$ & 42.4 & 50.0 & 45.6 \\
\hline
\end{tabular}

*Significant difference between sites $(P<0.05)$

${ }^{a} \mathrm{SD}$, standard deviation

${ }^{\mathrm{b}} \mathrm{kg}$, kilogram

${ }^{c}$ BMI, body mass index

${ }^{\mathrm{d}}$ Not compared between sites due to difference in measurement tools

e MMSE, mini-mental state examination 
f $3 \mathrm{MS}$, modified mini-mental state

${ }^{\mathrm{g}}$ MST, malnutrition screening tool

${ }^{\mathrm{h}}$ MNA-SF, mini nutritional assessment short-form

${ }^{\mathrm{i}}$ Malnourished according to ICD-10-AM classification of protein-energy malnutrition 
Table 3: Measures of diagnostic accuracy of the Malnutrition Screening Tool (MST) and Mini Nutritional Assessment-Short Form (MNA-SF) against the ICD10-AM classification of protein-energy malnutrition in a cohort of 57 older adults admitted to rural rehabilitation facilities in rural New South Wales, Australia

\begin{tabular}{|c|c|c|c|c|c|c|c|c|c|}
\hline & 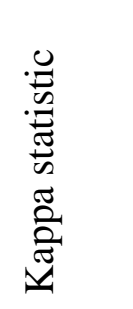 & 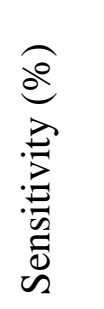 & 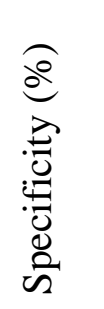 & 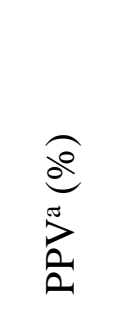 & $\begin{array}{l}\frac{a}{b} \\
0^{2} \\
z\end{array}$ & $\begin{array}{l}\stackrel{0}{0} \\
\text { م}\end{array}$ & 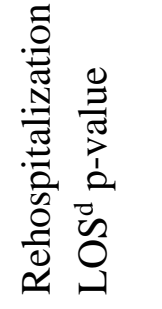 & 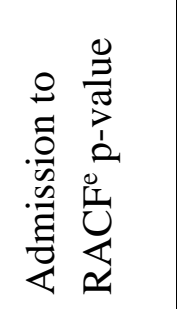 & 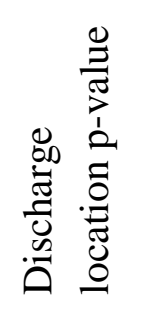 \\
\hline $\begin{array}{l}\mathrm{MST}^{\mathrm{f}} \\
\text { - value } \\
- \\
95 \% \mathrm{CI}^{\mathrm{g}}\end{array}$ & $\begin{array}{l}0.478^{\mathrm{h}} \\
0.193- \\
0.677\end{array}$ & $\begin{array}{l}80.8 \\
62.1- \\
91.5\end{array}$ & $\begin{array}{l}67.7 \\
50.1- \\
81.4\end{array}$ & $\begin{array}{l}67.7 \\
48.6- \\
83.3\end{array}$ & $\begin{array}{l}80.8 \\
60.6- \\
93.4\end{array}$ & $\begin{array}{l}8.8 \\
2.6- \\
30.2\end{array}$ & $P=0.975$ & $P=0.493$ & $P=0.556$ \\
\hline $\begin{array}{l}\text { MNA- } \\
\text { SF } \\
\text { - value } \\
-95 \% \mathrm{CI}\end{array}$ & $\begin{array}{l}0.210^{*} \\
0.020- \\
0.210\end{array}$ & $\begin{array}{l}100 \\
87.1- \\
100\end{array}$ & $\begin{array}{l}22.6 \\
11.4- \\
39.8\end{array}$ & $\begin{array}{l}52.0 \\
37.4- \\
66.3\end{array}$ & $\begin{array}{l}100 \\
58.9- \\
100\end{array}$ & $\begin{array}{l}15.2^{\mathrm{i}} \\
0.9- \\
233.3\end{array}$ & $P=0.174$ & $P=0.167$ & $P=0.125$ \\
\hline
\end{tabular}

${ }^{a} \mathrm{PPV}$, positive predictive value

${ }^{\mathrm{b}} \mathrm{NPV}$, negative predictive value

${ }^{\mathrm{c}} \mathrm{DOR}$, diagnostic odds ratio

${ }^{\mathrm{d}} \mathrm{LOS}$, length of stay

${ }^{\mathrm{e}} \mathrm{RACF}$, residential aged care facility

${ }^{\mathrm{f}}$ MST, malnutrition screening tool

${ }^{\mathrm{g}} \mathrm{CI}$, confidence interval

${ }^{\text {h }} P<0.0001$, "moderate agreement" as per Landis and Koch kappa statistic classification ${ }^{30}$.

${ }^{\mathrm{i}}$ The false negative values for the MNA-SF compared with the ICD-10-AM criteria were zero. However, due the problems with computation of odds ratios with a zero value, each cell in the contingency table had 0.5 added ${ }^{32-34}$. 